Article

\title{
Exploring the Role of 'Shadowing' as a Beneficial Preparatory Step for Sensitive Qualitative Research with Children and Young People with Serious Health Conditions
}

\author{
Natalie Tyldesley-Marshall 1, 2,3@ ${ }^{(}$, Sheila Greenfield ${ }^{2}$, Susan J. Neilson ${ }^{4}$, Jenny Adamski ${ }^{3}$, \\ Sharon Beardsmore ${ }^{3}$, Martin English ${ }^{3}$ and Andrew Peet ${ }^{1,3, * \text { (D) }}$ \\ 1 Institute of Cancer and Genomics, University of Birmingham, Birmingham B15 2TT, UK; \\ n.g.tyldesley-marshall@bham.ac.uk \\ 2 Institute of Applied Health Research, University of Birmingham, Birmingham B15 2TT, UK; \\ s.m.greenfield@bham.ac.uk \\ 3 Birmingham Children's Hospital, Steelhouse Lane, Birmingham B4 6NH, UK; jenny.adamski@nhs.net (J.A.); \\ sharon.beardsmore@nhs.net (S.B.); martinenglish@nhs.net (M.E.) \\ 4 School of Nursing, Institute of Clinical Sciences, University of Birmingham, Birmingham B15 2TT, UK; \\ s.j.neilson@bham.ac.uk \\ * Correspondence: a.peet@bham.ac.uk
}

Received: 14 November 2019; Accepted: 28 January 2020; Published: 30 January 2020

\begin{abstract}
This article aims to explore and record the role of shadowing in preparation for a qualitative study involving children and families with sensitive health issues. The researcher was engaged for a study involving qualitative research involving paediatric patients (those under 18 years old) and their families, but was unfamiliar with a hospital environment and interviewing children and young people (CYP) with a serious health condition. The researcher 'shadowed' healthcare professionals (HCPs) at a children's hospital during their day-to-day work in order to prepare for the research interviewing. From shadowing, the researcher gained: familiarity with a hospital environment, organisational processes, and medical terminology; an understanding of the appropriate ways to refer to patients; confidence and competence in talking to children with serious health conditions; and resilience to becoming upset during interviews while hearing patients' distressing stories-they became 'desensitised'. Shadowing can therefore be highly beneficial for researchers undertaking research in unfamiliar contexts, environments, and populations prior to interviewing.
\end{abstract}

Keywords: shadowing; qualitative research; research methodology; CYP; paediatric patients; interviews; sensitive research; chronic illness; brain tumours

\section{Introduction}

\subsection{What Is Shadowing}

'Shadowing' has a somewhat ambiguous character in social science due to its similarity to qualitative observation methods, especially that of participant-observation [1]. Though more commonly used as a data collection method in organizational research, it is not commonly recognized or critiqued in social science literature more generally [2]. This is at least partly due to the fact that shadowing is a technique used not for the purpose of social science but for vocational learning [3]. Shadowing, or observing another and what they "actually do in the course of their everyday lives" [3] (p. 1482) while carrying out their job, enabled the researcher to learn about the role, the tasks involved, and to supplement their understanding of the occupational environment [4]. 
In medicine, shadowing is commonplace in learning and is often expected to reinforce theory learnt in classrooms and expand knowledge [5,6]. As such, it is a normal component of the hospital environment, and young patients often feel that they are always watched by strangers [7]. Among others, the properties of shadowing that are distinct from observation methods are a focus on the individual (not department) for learning and understanding roles [1]. However, the shadowing this article subsequently describes was for the benefit of the researcher's understanding and did not involve a systematic collection of information for subsequent analysis [8]; therefore, it cannot be classified as research.

\subsection{Context of Research}

Though there had been studies exploring patients' views and understanding of their medical images [8-13], the perspectives and understandings of paediatric patients (those under 18 years) was a gap in the literature that needed addressing [12]. Shadowing was undertaken as a first step to gain a greater 'feel' and understanding of the context before the commencement of a study to explore what young patients with brain tumours and their families felt, understood, and valued from seeing Magnetic Resonance Images (MRIs) during their meetings with healthcare professionals (HCPs). Just as a literature review is a valuable prelude to research, though not research itself, shadowing was undertaken to better understand the perspectives of future research participants, the environment of the hospital that they frequently occupied, and how to converse with them to gain detailed and descriptive responses.

\section{3. 'Sensitive' Research}

For this study (for more detail and the main study interview results, see [14]), the focus was on the patient families' perceptions, opinions, and understandings of their world, and so a qualitative methodology seemed the most appropriate [15]. While there is no agreed upon definition of what a 'sensitive' topic is, it could generally be understood as those that are "private, stressful or sacred; could potentially cause stigmatisation or fear; and are areas of controversy or social conflict" [16] (p. 654). It is increasingly being recognised that being a researcher on a qualitative study, especially one involving listening to participants' painful or emotionally-charged experiences, such as those of a sensitive nature, can have a negative emotional impact on the researcher [17]. Measures such as debriefing, or 'self-care' should be taken to protect the mental well-being of the researcher, in order to avoid long-term effects such as vicarious traumatisation or 'burn out' $[17,18]$.

While the topics that are regarded as sensitive often vary based on context, as well as cultural norms and the values of those undertaking the research [16], much health research "focuses on aspects of life that may be considered sensitive" [19] (p. 12). Being a parent of a child with a serious health condition, such as brain tumours, is known to be stressful [20]; and research on the topic potentially causes them "anxiety about reawakening painful memories" [21] (p. 507). While the parents of children with any form of cancer fear for their future,

"within cancer types differences in experiences have been shown, with, for examples, pediatric [sic] patients' parents experiencing more fear if their child had a brain tumour than if they had leukaemia" [22] (p. 2).

Children and young people (CYP) are often deemed to have "relative vulnerability" compared to adults [23], were also going to be asked to recall potentially painful experiences of illness and hospitalisation, which might cause anxiety, discomfort, or fear [24].

For the study, a research fellow with experience in qualitative research methods was therefore engaged, though they were a layman to the research environment. Not being from a HCP background, familiar with a hospital environment, or in speaking to children with a 'serious' health condition, were seen as important knowledge gaps to address [25], and shadowing HCPs, where the study was based, was seen as a way to address them. This article aims to explore and record the role of shadowing in preparation for a qualitative study involving children and families with sensitive health issues. 


\section{Methods}

\subsection{Ethics}

All subjects gave their informed consent for inclusion before they participated in the study that the shadowing was in preparation for. The protocol was approved by the West Midlands Black Country Research Ethics Committee (WM/16/WM/0490).

\subsection{Preparing for the Study: Prior to Shadowing}

A number of steps were taken by the researcher in order to prepare for undertaking the study: reviewing the literature, speaking with HCPs, observing and taking notes, asking questions, and writing up notes and reflecting (Table 1).

Table 1. Steps taken by the researcher to prepare for interviewing children and young people (CYP) with serious conditions (including shadowing).

\begin{tabular}{|c|c|}
\hline Activity & Aim \\
\hline Reviewing the literature & $\begin{array}{l}\text { Gain an understanding of the issues and 'journey' for the } \\
\text { participants that may be discussed in interviews. } \\
\text { Gain experience of hearing similar emotive experiences to } \\
\text { desensitise to them. }\end{array}$ \\
\hline $\begin{array}{l}\text { Approach healthcare professionals (HCPs) to arrange } \\
\text { meetings }\end{array}$ & $\begin{array}{l}\text { Learn about processes, culture, and rationales for the 'way } \\
\text { things are done' (or supposed to be done) from } \\
\text { HCP perspective. }\end{array}$ \\
\hline Shadowing: & $\begin{array}{c}\text { Gain 'feel' of environment, culture and medical } \\
\text { terminology in process. }\end{array}$ \\
\hline Observing and taking notes & $\begin{array}{r}\text { Gain experience of hearing similar emotive experiences to } \\
\text { desensitise to them. }\end{array}$ \\
\hline $\begin{array}{l}\text { Asking HCPs focussed follow-up questions } \\
\text { (when appropriate) }\end{array}$ & $\begin{array}{l}\text { Clarifying terms, nuances in language, actions, and } \\
\text { reasoning not fully understood. }\end{array}$ \\
\hline Writing up notes and reflecting & $\begin{array}{l}\text { Making learning more explicit, and clarifying what not } \\
\text { fully understood. }\end{array}$ \\
\hline
\end{tabular}

\subsubsection{Reviewing the Literature}

In preparation for interviewing, the researcher read journal articles and books on: the 'power' of the image [8,26]; how patients (and their families) understand and experience living with cancer [27,28]; how doctors communicate results and medical information [29]; epistemology and methods for researching in health [15,30]; methods for researching CYP [31,32]; experiences of hospitalised children on aspects of their care [27,33]; and NHS information for young patients with brain tumours [34]. In addition, the researcher watched online videos of children with brain tumours describing their experiences $[35,36]$.

The Principal Investigator (PI) was keen that the researcher would become less likely to be distressed hearing about a family's experiences during a research interview, which could negatively affect the researcher and research-they hoped to desensitise the researcher. Desensitising is a part of HCPs' socialisation into the role and helps them to cope with the emotional demands of their work [37]. After this literature review, the researcher did feel less likely to become distressed while hearing the patients' and parents' stories. Desensitising was also an anticipated outcome for the shadowing.

\subsubsection{Speaking to HCPs}

The researcher spoke to HCPs based at the children's hospital where the research was to be based, including paediatric oncologists and nurse specialists, about how they showed MRI images to families, the various responses they received from families, and the perceived benefits for families. This helped the researcher learn the usual processes and rationales for interacting with patient families regarding MRIs. 
HCPs also arranged mornings or afternoons when the researcher could shadow them. Due to the consideration for the families by the HCPs, families were not shadowed when they were in an acutely challenging period, such as being told of a relapse (their tumour returns after being surgically removed or reduced by chemotherapy or radiotherapy), or that they were starting palliative care (care needed for those at the end of their life).

\subsection{Steps in Shadowing}

\subsubsection{Appearance and Body Language}

The researcher wore dark clothing to be less 'eye-catching', aiming to 'blend into the background'. The HCPs would explain to the patient family the purpose of shadowing at the outset and gain verbal consent for the researcher to be present. The researcher was prepared to wait out of sight and earshot if the family objected to their presence, although none did. (The researcher wore a hospital identity card in order to access the hospital, which may have given the mistaken impression that they were a HCP, though it no doubt enhanced the legitimacy of their presence.) When introduced, the researcher smiled at first, sometimes said 'Hi' then avoided eye contact and tried to become invisible to the family they were shadowing. Obviously, anything heard was confidential.

The meetings observed were mostly 'check ups' or 'routine' appointments to discuss scan results or new symptoms found in the young patients. (None had their diagnosis or a relapse disclosed to them in the presence of the researcher.)

In meetings, the researcher would sit in the corner, away from the family, not interrupting or distracting the conversation. On the wards and other sites, they tended to stay close to the person they were shadowing, and not position themselves between the HCP/s and the CYP. Generally, their body positioning was 'open' to avoid being intimidating or intrusive, for example, they did not cross their arms, nor sit close enough to the families to invade their 'personal space'. The researcher tended to keep still and aimed to be unnoticed by the family. They kept their expression neutral or lightly smiling so as to be non-threatening and to avoid attention [38].

\subsubsection{Observing and Taking Notes}

The researcher aimed to observe as much detail as possible: what people said, how they said it, and their body language. Whilst the researcher discreetly carried a pen and a small notebook (or a piece of paper) to take notes, they only used these when they felt this would not be a distraction, and would not make the patient family feel uncomfortable or less willing to discuss things with their healthcare team. Any words or events that stood out as interesting or unusual were jotted down (such as the researcher's surprise at how often the word 'poo' was used) and wrote up in full as soon as the researcher got an opportunity to reflect on them later.

\subsubsection{Asking Questions of the HCPs}

The researcher tried to keep an open mind, to not assume anything, and always be thinking of questions to ask HCPs, such as 'What is that?', 'Why are you doing that?', or 'What's that noise?'. After the patient family had left the room or were out of earshot, the researcher was able to ask the HCPs questions to clarify anything not understood, while always being careful to maintain confidentiality. The researcher also had the possibility of being able to make comments to HCPs such as 'I never would have realised $x !$ ' or 'They were really interested in $y !$ ', which would often lead to an explanation from HCPs and the development of the researcher's understanding. ' $X$ 's parent is on a food restriction diet at the moment, which might be why they were so focussed on their child's eating, while the child thinks they're eating as usual.' Or 'Yes. Bowel movements and their contents are some of the main concerns that parents have when coming to see us. Cancer and its treatments frequently mess up these rhythms' [39]. 


\subsubsection{Reflecting}

In their head, the researcher could often still hear the words, accent, tone, and pitch of the observed speakers, as well as facial expressions and body language, for hours afterwards. They would aim to write up notes in full as soon as possible to aid accurate recollection. Writing up the reflections became quicker as they became more familiar with the process. Previously meaningless acronyms and terminology became familiar (though not necessarily more intelligible) to the researcher, so writing was a way to ensure that they did "not necessarily adopt or reproduce" [40] (p. 19) the views of the HCPs or families, but instead interpret and reflect on them.

The researcher wrote about more descriptive elements, such as what happened or was discussed in that specific session, and used square brackets to separate questions, assumptions, feelings, and 'impressions' (how they 'read' people or situations, for example, 'This is something close to their heart').

Sometimes it would help to print the notes out, so that the researcher could 'see' what was actually written. They would then 'tidy up' the document, linking thoughts and information and rearranging sentences and paragraphs so that they would read more coherently. They considered how the direct words or phrasing from patients (especially more colloquial expressions) might be misinterpreted by a reader (or themselves in the future) as well as thinking about how they could make sentences clearer and more succinct.

They would reflect on and highlight any similarities or differences to previous shadowing sessions, if these were brought to mind. They reflected on why there might be similarities or differences in order to make wider patterns or generalisations that might be useful when interviewing. The researcher found it easier to just write down everything they could think of (as in a stream of consciousness) and then return to it after working on a completely different task or the next day. If more stories or thoughts came to them when re-reading, then these were added.

Though they found it difficult, the researcher forced themselves to be honest and, self-critical, by adding how they thought they could have been more effective during shadowing and whether they might have misunderstood words or contexts. Initially, they only observed while 'shadowing', though eventually took a more active role. From the notes made during the shadowing process, four major areas of benefit emerged: a greater familiarity with the hospital environment and processes; an appropriate use of language and terminology; talking with CYP with serious health conditions; and desensitisation (Table 2). 
Table 2. Illustrative examples from shadowing notes.

\begin{tabular}{|c|c|}
\hline Area of Benefit & Illustration Extract from Shadowing Notes \\
\hline Greater familiarisation with hospital environment and processes & $\begin{array}{l}\text { I asked what the noise was that I could hear, and was told that it was an IV [intravenous] } \\
\text { drip after being asked 'You've never been on the wards before then?' } \\
\text { (Nurse Specialist 2, Ward, p. 5) }\end{array}$ \\
\hline Appropriate use of language and terminology & $\begin{array}{l}\text { The first patient had had many investigations after being diagnosed, and many problems } \\
\text { that didn't seem linked to their cancer. [I have never heard the word 'poo' used so } \\
\text { frequently in a half hour session.] (Nurse Specialist } 1 \text { and Oncologist, Clinic, p. 4) }\end{array}$ \\
\hline Talking with CYP with serious health conditions & $\begin{array}{l}\text { The YW [Youth Worker] took a cue from the patient's shirt. 'I don't think you're wearing a } \\
\text { Star Wars shirt as a random thing.' The YW asked about whether they had seen Episodes } \\
4-6 \text {, and said that that was what their generation had watched. [I reflected that making } \\
\text { explicit the age gap would be something I would avoid doing since I would assume that it } \\
\text { would make YP [young people] focus on the differences between us or think that they } \\
\text { couldn't 'relate' to me.] (Youth Worker 1, Ward, p. 23) }\end{array}$ \\
\hline ‘Desensitising' (against emotional upset) & $\begin{array}{l}\text { I found it upsetting to be next to a child who was continuously crying and after hearing all } \\
\text { the things they had been through, and the long term damage that their necessary and } \\
\text { unavoidable treatment had caused, and had to stop myself from crying in the ward. [... I I } \\
\text { am aware that if I start thinking about it again and think about having to explain it, it will } \\
\text { set me off again so I will avoid this for a while. I guess that this is what the PI [Principal } \\
\text { Investigator] wants to desensitise me to ... ] (Nurse Specialist 2, Ward, p. 6) }{ }^{1}\end{array}$ \\
\hline
\end{tabular}




\section{Results: Benefits from Shadowing}

For six months, prior to the study, oncologists and nurse specialists were shadowed in 'consultations' (meetings with the patient families to discuss a patient's progress, effects of treatments, and scan results) or on the hospital wards on their regular clinical duties. Occasionally they were shadowed off-site while they were interacting with patients and their families. Youth workers and play facilitators were shadowed in the play centre or off-site buildings (Table 3).

Table 3. Number of shadowing sessions and roles shadowed.

\begin{tabular}{cccccc}
\hline Role (Number Shadowed in Role) & Sessions & Clinic & Wards & Play Centre & Offsite \\
\hline Youth worker (2) & 8 & 0 & 5 & 0 & 3 \\
Nurse specialist (2) & 5 & 0 & 4 & 0 & 1 \\
Paediatric oncologist and nurse specialist (1) & 3 & 3 & 0 & 0 & 0 \\
Play specialist (2) & 2 & 0 & 2 & 0 & 0 \\
Play \& recreation facilitator (2) & 2 & 0 & 0 & 2 & 0 \\
\hline
\end{tabular}

\subsection{Greater Familiarity with Hospital Environment and Processes}

Shadowing familiarised the researcher with the hospital environment (the sights and sounds to which the researcher was unaccustomed, such as the electronic intravenous fluid drip). This also taught the researcher useful codes of conduct, such as dress codes (short sleeves on the wards due to infection control rules), which was found useful when undertaking interviews on wards, including one in an isolation room.

The researcher had also imagined that the children's cancer ward would be a relatively quiet place, with a lot of upset or scared-looking children, and sombre-looking families. This was not the case. The ward was often quite noisy, with families experiencing "fun, joy, living and learning" [27] (p. 341), and the families usually smiled upon the HCP's approach.

In the literature review, the researcher had read about different 'patient pathways', or ways to reach the consultant-referral from a general practitioner (GP) for symptoms or from, for example, a hit to the head, which resulted in a scan that discovered a brain tumour. However, through speaking with HCPs, these concepts became less abstract and more tangible when hearing patient families talk about how they progressed through the hospital systems and departments, and their 'battles' and delays to get their child seen by the relevant doctors and diagnosed [41].

In shadowing a nurse specialist at a school meeting where they were joined by a parent, a head of department, a physiotherapist, and other school representatives, discussing past care and the challenges the patient faced, it dawned on the researcher how many individuals, and what a wide range of professions and organisations can be needed to support the healthcare of just one patient. They realised that the clinical management of children with cancer is a truly team effort, with many different skills being required, as well as the need to collaborate and communicate effectively [42].

\subsection{Appropriate Use of Language}

From shadowing, the researcher learnt that patient families tended to use more specific medical terms, rather than the word 'cancer', and they often understood (or at least used) medical terminology readily in discussions. Patients and families often become experts in their / child's conditions [43], though presumably they also found these words were far less emotive.

The researcher also learnt that HCPs almost always referred to patients as 'a patient with a brain tumour' rather than a 'brain tumour patient', to avoid identifying a person by their disease or condition. 'Poo' was a term used matter-of-factly by HCPs and families, matching the matter-of-fact tone of many parents for many of these conversations [44].

Shadowing familiarised the researcher somewhat with medical terminology. Though the researcher would not necessarily understand when and why certain terms were necessary, from the way words 
were used in discussions, the researcher could deduce, for example, 'Temozolomide' was a medication, and that a 'shunt' was a piece of medical equipment.

The researcher noted that parents seemed to be pre-eminently concerned about the eating habits and the bowel movements of their child. One of the HCPs shadowed commented that food was one of the few things that a parent of a child with cancer could exert control over [39].

\subsection{Talking with Children and Young People (CYP) with Serious Health Conditions}

Initially, the researcher simply observed during shadowing. However, some of the HCPs strongly persuaded the researcher to have a more interactive role and to talk (and even play) with the patients, arguing that only so much could be learnt from observing and must be learnt through 'doing' - that is, directly conversing with the patients.

When the researcher tried this, they found that, as many HCPs had informed them, 'every child is different'. There was still a lot of 'trial and error' in finding out how to get each young person talking, and the researcher often had to draw on games being played, online videos or DVDs being watched, or nearby branded/themed objects (such as Pokémon or football clothing, toys or paraphernalia in the room) for conversational starting points. They found that there were no real taboo questions in asking an adolescent patient about their illness or treatment, especially when the questions were prefaced by a qualifier such as 'Is it alright if I ask ... ?' On the contrary, most CYP seemed to find these to be topics that they were comfortable talking about, and had much to say.

Feedback from the HCPs on Shadowing

Though the researcher did not seek feedback on their shadowing, or their ability to build rapport with CYP with serious conditions, some HCPs shadowed offered this. After the researcher had been shadowing a number of youth worker sessions, they were asked by a patient who they were, and 'without thinking', the researcher echoed a response that they'd heard the youth worker say a number of times, and replied "I'm a stalker". The patient (and youth worker) laughed and was then more comfortable and relaxed with a stranger observing. The youth worker later congratulated the researcher on how far they'd come; correctly read the patient, their sense of humour, and the situation as one where this 'jokey' comment would be acceptable, be correctly interpreted, and would build rapport.

\subsection{Desensitising the Researcher}

On one occasion while shadowing, a child aged around 1 was crying for over an hour, as they needed to be almost continually moved to be monitored and have tests in their hospital bed. After listening to this crying for over an hour, in addition to hearing their parent talk about the dozens of operations, procedures and treatments the child had been through, and that the muscles in their legs had wasted away due to having to spend so much time in hospital beds, the researcher was very affected.

The PI viewed this as beneficial, and that after more contact and similar experiences, the likelihood of the researcher becoming distressed hearing about a family's experiences during the course of an interview would be minimized, i.e., they were becoming desensitised [37].

\section{Reflections on Benefits from Shadowing}

\subsection{Hospital Processes and Environment}

Shadowing gave the researcher a "taste of clinical medicine" [5] (p. 634) and familiarity with the processes and environment, such as medical equipment and the hospital wards.

\subsection{Appropriate Use of Language}

Prior to shadowing, one of the researcher's greatest concerns in talking with patient families was in saying the 'wrong thing' or asking a question on a taboo topic. Through shadowing, they found that one should not assume what patients, or their families, will find distressing, and that 
children were often seemingly unfazed by answering questions on what the researcher considered a 'sensitive' topic. In a similar vein, Solberg (2014) found that children that had experienced or witnessed domestic violence were not necessarily upset discussing it, though they sensed "uneasiness" when one participant suspected that they were about to be asked why their mother did not intervene [45] (p. 239). Many parents also seemed to enjoy the experience of talking about this subject to an interested listener. Indeed, other researchers have noticed the 'therapeutic' or cathartic effect that those answering questions for interviews report [46]. The researcher also experienced an interview for the study where the parent did not display any distress when recounting an occasion where they thought that their child would die, though they needed tissues when discussing their child being bullied.

Though interviews often draw more implicitly on the personal experience of the researcher in developing the interview questions and the research design, such as a mother interviewing women about their experiences of pregnancy [47], it is not always the case that a researcher has that level of familiarity with the research setting. When preparing for ethnographic fieldwork (which draws on a range of research methods such as observation, documentary analysis and interviews), a key part of gaining trust and establishing relationships is to learn not only the words used by the group you are observing, but the context in which they are spoken [48]. Understanding this can lead to a new perspective and new insights, though when undertaking a study using interviews alone, this part is omitted.

Though there are benefits of being a member or 'insider' of a group, from long-term or highly implicit understandings that an 'outsider' would most likely miss [38]. A greater benefit is seen from being an outsider, or at least in some ways unfamiliar to the setting. This allows the researcher to 'stand back' and be able to see the interactions or events occurring in front of them as noteworthy, strange, or needing explanation to an outsider. However, in reality, most settings are a mixture of strange and familiar elements (such as a teacher researching in a school that they have never taught in), so it is more a matter of degree rather than a researcher being a complete 'insider' or 'outsider' [47]. Shadowing could be conceived as a useful way to gain access to 'insider knowledge' without having to gain the status of an 'insider'.

\subsection{Talking with CYP with Serious Health Conditions}

While many qualitative research methods textbooks, and journal articles focussing on methodological issues aver the importance of building rapport with young participants [19,24,48-52] in order to get rich, detailed data,

"The rapport that develops between researcher and child is important for encouraging more forthcoming responses" [48] (p. 166),

very few explain how to go about this beyond "The interviewer asked questions or made comments about the child's personal life, such as family, school, and hobbies" [52] (p. 158), or "small talk about the weather, work, participants' children and how their days had been progressing" [19] (p. 14). The researcher found literature on researching CYP with serious health conditions was quite lacking in specific detail on techniques for building rapport, beyond using their first name and clarifying that they were not a doctor or nurse [53], or maintaining a "flexible and creative atmosphere" [24] (p. 351).

Though in a recent methods book on research with CYP [23], the researcher found reference to starting interviews with "an easy ice-breaker topic, game or creative method" (p. 117) and that time invested making CYP "feel comfortable is time well spent" (p. 112), as "the more relaxed the children or young people feel [ ... ] with the researchers and with the research, the more honest, open and interactive they will be" (p. 110). This methods book also explicitly covers 'sensitive topics' - anticipating these, using appropriate methods, and how to respond should CYP become distressed. Conversely, the researcher found that literature on researching sensitive issues tended not to consider CYP [54], and if they did, not to the level of detail of building rapport with them, regardless of a serious health condition [55].

However, there are a few exceptions. Bluebond-Langner's (1978) seminal work 'The Private Worlds of Dying Children' does detail that they introduce themselves, explain their role, then ask children 
whether they can join them in colouring, drawing, or whatever the child was currently preoccupied with. (The researcher was even occasionally "tested"' to watch TV in silence until the child decides that they are "OK" and will answer questions) [53] (p. 247).) However, Bluebond-Langer's (1978) research took place over months, with opportunities for daily contact to build and establish relationships with the CYP [53], which is not available for studies where participants are interviewed once.

Although in the study that the shadowing reported in this paper was undertaken in preparation for, the researcher did arrange a session prior to the interviews where they coloured, drew, talked or played games with the CYP in order to make them more comfortable with the researcher and when speaking with them [14]. The researcher found that engaging and talking with children with serious health conditions requires a more "practical mastery", an "implicit and pre-reflective feel ... which guides action within social arenas" [56] (p. 359). 'Practice' of these skills from shadowing can help with their acquisition, increasing ease and comfort when talking to CYP and building rapport.

\subsection{Desensitising the Researcher}

Although the researcher had been a little 'teary-eyed' watching online videos of children [35] with cancer talking about their experiences in preparation for the study, they had viewed themselves as not that likely to become distressed. They were subsequently surprised that after hearing a parent's account of their child's experiences, they were so much more affected than they expected. (Not unlike the title of an unrelated qualitative study, "I can't say I wasn't anticipating it, but I didn't see it coming in this magnitude" [57].)

Regular meetings with the research team for the researcher to debrief-express their emotions in a safe environment-are often recommended after shadowing in a clinical environment [58] or interviewing on a sensitive topic [18,59]. Given that the multidisciplinary team were disparately located, these debriefing sessions were more ad hoc, though after a few shadowing sessions, the researcher did not feel that they needed further debriefing.

\section{Limitations}

Due to the HCPs' concern for the emotional welfare of families, families were not shadowed when they were in an acutely challenging period, such as having recently being informed of a relapse, or that they were starting palliative care. Therefore, patient families shadowed may differ in certain respects, especially concerning their openness and willingness to talk about the illness and current treatments.

\section{Conclusions}

In conclusion, shadowing in preparation for sensitive research with children and young people (CYP) can provide a researcher with:

- Familiarity with an unfamiliar hospital environment and processes;

- Familiarity with medical terminology and appropriate language to use around children and young people with serious health conditions;

- Confidence and competence in talking with children with serious health conditions through gathering direct experience of how healthcare professionals (HCPs) interact with patient families within existing healthcare contexts; and

- Emotional desensitisation against upsetting stories from participants during interviews by hearing similar stories in advance.

Shadowing can thus be highly beneficial for researchers undertaking a study in unfamiliar contexts, environments, and populations. The literature on specific techniques to establish rapport when interviewing CYP with serious health conditions was found to be somewhat lacking.

\section{Recommendations}

Shadowing in healthcare research is recommended in the following situations: 
- When researchers are interviewing those with a serious health condition for the first time;

- When researchers are conducting semi- or unstructured interviews with children for the first time; or

- When researchers are interviewing in social contexts that are unfamiliar to them, such as a hospital.

\section{Specific Recommendations when Researching CYP with a Brain Tumour, and Their Families}

- Refer to patients with [condition], rather than [condition] patients, to keep you aware that they are a person first, though with a condition.

- Parents will most likely use the specific name of the tumour, rather than 'cancer'. Follow their lead.

- 'Poo' will most likely be discussed, and is not viewed as a childish or 'silly' term

- Do not be afraid to ask for clarification on medical terminology that you do not understand. They will be used to doing so.

- Though you should aim to be tactful and avoid distress when discussing their illness and treatment, be aware that seemingly 'less important', 'less distressing', or 'more everyday' topics may be the ones that they become upset over.

- Occasions to 'practice' speaking and building rapport with children with serious conditions prior to the research will be invaluable. Shadow (or volunteer) at a hospice or hospital, or offer to babysit friends' children with such conditions.

Author Contributions: Conceptualization, A.P., S.G., S.J.N., J.A., S.B., M.E., and N.T.-M.; methodology, A.P., S.G., S.J.N. and N.T.-M.; formal analysis, A.P., S.G., S.J.N. and N.T.-M.; investigation, N.T.-M.; writing-original draft preparation, N.T.-M.; writing-review and editing, A.P., S.G., S.J.N., J.A., S.B., M.E., and N.T.-M.; supervision, A.P., S.G., and S.J.N.; project administration, N.T.-M.; funding acquisition, A.P. All authors have read and agreed to the published version of the manuscript.

Funding: The initial research was funded by a National Institute of Health Research (NIHR) Research Professorship NIHR-RP-R2-12-019 awarded to AP.

Acknowledgments: We are grateful to all of our participants and the Research Advisory Group for their insights, and to the University of Birmingham's Children's Brain Tumour Research Trust that gave feedback on the earlier presentations related to the study. We also thank colleagues that gave their insights and time, Gerard Millen, Beryl Rodrigues, Albert Farre, Desi Rogues, Emma Eardley, Helen Woodman and many others that supported us.

Conflicts of Interest: The authors declare no conflict of interest. The funder and sponsor had no role in the design of the study; in the collection, analyses, or interpretation of data; in the writing of the manuscript, or in the decision to publish the results.

\section{References}

1. Bartkowiak-Theron, I.; Sappey, J.R. The methodological identity of shadowing in social science research. Qual. Res. J. 2012, 12, 7-16. [CrossRef]

2. McDonald, R. Studying actions in context: A qualitative shadowing method for organizational research. Qual. Res. 2005, 5, 455-473. [CrossRef]

3. Quinlan, E. Strategy Conspicuous Invisibility: Shadowing as a Data Collection. Qual. Inq. 2008, 14, 1480-1499. [CrossRef]

4. Myers, K.K.; Jahn, J.L.S.; Gailliard, B.M.; Stoltzfus, K. Vocational Anticipatory Socialization (VAS): A Communicative Model of Adolescents' Interests in STEM. Manag. Commun. Q. 2011, 25, 87-120. [CrossRef]

5. Iwata, K.; Gill, D. Learning through work: Clinical shadowing of junior doctors by first year medical students. Med. Teach. 2013, 35, 633-638. [CrossRef] [PubMed]

6. Paskiewicz, L.S. The shadowing experience: Valuing the link between faculty practice and student learning. J. Prof. Nurs. 2002, 18, 238-242. [CrossRef]

7. Sheffield University. Space to Care: Children's Perceptions and Experiences of Hospital Space. Available online: https://www.sheffield.ac.uk/polopoly_fs/1.221751!/file/Research-briefing_James_spacetocare.pdf (accessed on 6 November 2019).

8. Rhodes, L.A.; McPhillips-Tangum, C.A.; Markham, C.; Klenk, R. Power of the visible: The meaning of back diagnostic tests in chronic back pain. Soc. Sci. Med. 1999, 48, 1189-1203. [CrossRef] 
9. The, A.; Hak, T.; Koeter, G.; van de Wal, G. Radiographic images and the emergence of optimism about recovery in patients with small cell lung cancer: An ethnographic study. Lung Cancer 2003, 41, 113-120. [CrossRef]

10. Blaxter, M. The case of the vanishing patient? Image and experience. Sociol. Health Illn. 2009, 31, 762-778. [CrossRef]

11. Von Wagner, C.; Knight, K.; Halligan, S.; Atkin, W.; Lilford, R.; Morton, D.; Wardle, J. Patient experiences of colonography, barium enema and CT colonography: A qualitative study. Br. J. Radiol. 2009, 82, 13-19. [CrossRef]

12. Carlin, L.; Smith, H.E.; Henwood, F. To see or not to see: A qualitative interview study of patients' views on their own diagnostic images. BMJ Open 2014, 4, e004999. [CrossRef] [PubMed]

13. Makanjee, C.R.; Bergh, A.; Hoffmann, W.A. Healthcare provider and patient perspectives on diagnostic imaging investigations. Afr. J. Prim. Health Care Fam. Med. 2015, 7. [CrossRef] [PubMed]

14. Tyldesley-Marshall, N.; Greenfield, S.; Neilson, S.; English, E.; Adamski, J.; Peet, A. Qualitative study: Patients' and parents' views on brain tumour MRIs. Arch. Dis. Child. 2019. [CrossRef] [PubMed]

15. Grbich, C. Qualitative Research in Health; Sage Publishing: London, UK, 1999.

16. Powell, M.A.; McArthur, M.; Chalmers, J.; Graham, A.; Moore, T.; Spriggs, M.; Taplin, S. Sensitive topics in social research involving children. Int. J. Soc. Res. Methodol. 2018, 21, 647-660. [CrossRef]

17. Dickson-Swift, V.; James, E.L.; Kippen, S.; Liamputtong, P. Doing sensitive research: What challenges do qualitative researchers face? Qual. Res. 2007, 7, 327-353. [CrossRef]

18. Mallon, S.; Elliott, I. The emotional risks of turning stories into data: An exploration of the experiences of researchers working on sensitive topics. Societies 2019, 9, 62. [CrossRef]

19. Elmir, R.; Schmied, V.; Jackson, D.; Wilkes, L. Interviewing people about potentially sensitive topics. Nurse Res. 2011, 19, 12-16. [CrossRef] [PubMed]

20. Hutchinson, C.; Willard, V.W.; Hardy, K.K.; Bonner, M.J. Adjustment of caregivers of pediatric patients with brain tumors: A cross-sectional analysis. Psycho-Oncol. J. Psychol. Soc. Behav. Dimens. Cancer 2009, 18, 515-523. [CrossRef]

21. Scott, D.A.; Valery, P.C.; Boyle, F.M.; Bain, C.J. Does research into sensitive areas do harm? Experiences of research participation after a child's diagnosis with Ewing's sarcoma. Med. J. Aust. 2002, 177, 507-510. [CrossRef]

22. Anclair, M.; Hovén, E.; Lannering, B.; Boman, K.K. Parental fears following their child's brain tumor diagnosis and treatment. J. Pediatric Oncol. Nurs. 2009, 26, 68-74. [CrossRef]

23. Brady, L.; Graham, B. Social Research with Children and Young People: A Practical Guide; Policy Press: Bristol, UK, 2019.

24. Huang, X.; O'Connor, M.; Ke, L.-S.; Lee, S. Ethical and methodological issues in qualitative health research involving children. Nurs. Ethics 2014, 23, 339-356. [CrossRef] [PubMed]

25. Savvakis, M.; Tzanakis, M. The Researcher, the Field and the Issue of Entry: Two Cases of Ethnographic Research concerning Asylums in Greece. Sociol. Res. Online 2004, 9, 1-12. [CrossRef]

26. Kevles, B.H. Naked to the Bone: Medical Imaging in the Twentieth Century; Addison-Wesley: New Brunswick, NJ, USA, 1997.

27. Sposito, A.M.P.; Silva-Rodrigues, F.M.; de Cassia Sparapani, V.; Pfeifer, L.L.; de Lima, R.A.G.; Nascimento, L.C. Coping strategies used by hospitalized children with cancer undergoing chemotherapy. J. Nurs. Scholarsh. 2015, 47, 143-151. [CrossRef] [PubMed]

28. Deimling, G.T.; Bowman, K.F.; Sterns, S.; Wagner, L.J.; Kahana, B. Cancer-related health worries and psychological distress among older adult, long-term cancer survivors. Psycho-Oncol. J. Psychol. Soc. Behav. Dimens. Cancer 2006, 15, 306-320. [CrossRef] [PubMed]

29. Redshaw, M.E.; Harvey, M.E. Explanations and information-giving: Clinician strategies used in strategies used in talking to parents of pre-term infants. BMC Pediatrics 2016, 16, 25. [CrossRef] [PubMed]

30. Bowling, A. Research Methods in Health: Investigating Health and Health Services, 3rd ed.; Oxford University Press: Maidenhead, UK, 1999.

31. Fox, R. Resisting participation: Critiquing participatory research methodologies with young people. J. Youth Stud. 2013, 16, 986-999. [CrossRef]

32. Coyne, I.; Hayes, E.; Gallagher, P. Research with hospitalized children: Ethical, methodological and organizational challenges. Childhood 2009, 16, 413-429. [CrossRef] 
33. Da Silva, L.F.; Cabral, I.E. Rescuing the pleasure of playing of child with cancer in a hospital setting. Rev. Bras. Enferm. 2015, 68, 337-342. [CrossRef]

34. NHS website. MRI Scan. Available online: http://www.nhs.uk/conditions/MRI-scan/Pages/Introduction.aspx (accessed on 3 November 2015).

35. Help Harry Help Others. Watch Harry's Story. Available online: https://hhho.org.uk/ (accessed on 5 November 2015).

36. Poppy Fields. Available online: http://www.poppyfieldsappeal.co.uk/ (accessed on 9 November 2015).

37. Kuczewski, M.G.; McCarthy, M.P.; Michelfelder, A.; Anderson, E.E.; Wasson, K.; Hatchett, L. “I will never let that be OK again": Student reflections on competent spiritual care for dying patients. Acad. Med. 2014, 89, 54-59. [CrossRef]

38. Arber, A. Reflexivity: A challenge for the researcher as practitioner? J. Res. Nurs. 2006, 11, 147-157. [CrossRef]

39. Young, B.; Dixon-Woods, M.; Findlay, M.; Heney, D. Parenting in a crisis: Conceptualising mothers of children with cancer. Soc. Sci. Med. 2002, 55, 1835-1847. [CrossRef]

40. Charmaz, K. Grounded Theory: A Practical Guide; Sage: London, UK, 2006.

41. Carmichael, N.; Tsipis, J.; Windmueller, G.; Mandel, L.; Estrella, E. “Is it Going to Hurt?": The Impact of the Diagnostic Odyssey on Children and Their Families. J. Genet. Couns. 2015, 24, 325-335. [CrossRef] [PubMed]

42. Llewellyn-Jones, G.; Pereira, J. Radiological input during paediatric multidisciplinary team meetings and its influence on clinical patient management. J. Med. Imaging Radiat. Oncol. 2016, 60, 206-209. [CrossRef] [PubMed]

43. Kennedy, I. Patients are experts in their own field: The interests of patients and healthcare professionals are intertwined. BMJ 2003, 326, 1276. [CrossRef] [PubMed]

44. Kelly, D.; Pearson, S.; Mulhall, A. 'Being in the same boat': Ethnographic insights into an adolescent cancer unit. Int. J. Nurs. Stud. 2004, 41, 847-857. [CrossRef] [PubMed]

45. Solberg, A. Reflections on interviewing children living in difficult circumstances: Courage, caution and co-production. Int. J. Soc. Res. Methodol. 2014, 17, 233-248. [CrossRef]

46. Walls, P.; Parahoo, K.; Fleming, P.; McCaughan, E. Issues and considerations when researching sensitive issues with men: Examples from a study of men and sexual health. Nurse Res. 2010, 18, 26-34. [CrossRef]

47. Burgess, R.G. In the Field: An Introduction to Field Research; Routledge: London, UK, 2004.

48. Fine, A.; Sandstrom, K.L. Knowing Minors: Participant Observation with Minors; Sage: London, UK, 1988.

49. Aldgate, J.; Bradley, M. Children's experiences of short-term accommodation. In The Reality of Research with Children and Young People; Lewis, V., Kellett, M., Robinson, C., Fraser, S., Ding, S., Eds.; Sage: London, UK, 2004; pp. 67-86.

50. Duncan, R.E.; Drew, S.E.; Hodgson, J.; Sawyer, S.M. Will my mum hear this? Methodological and ethical challenges in qualitative health research with children and young people. Soc. Sci. Med. 2009, 69, 1691-1699. [CrossRef]

51. Coad, J.; Gibson, F.; Horstman, M.; Milnes, L.; Randall, D.; Carter, B. Be my guest! Challenges and practical solutions of undertaking interviews with children in the home setting. J. Child Health Care 2014, 19, 432-443. [CrossRef]

52. Teoh, Y.; Lamb, M.E. Preparing children for investigative interviews: Rapport-building, instruction and evaluation. Appl. Dev. Sci. 2010, 14, 154-163. [CrossRef]

53. Bluebond-Langnet, M. The Private Worlds of Dying Children; Princeton University Press: Princeton, NJ, USA, 1978.

54. Lee, R.M. Doing Research on Sensitive Topics; Sage: London, UK, 1993.

55. Lee, Y.-O.; Lee, R.M. Methodological research on 'sensitive' topics: A decade review. Bull. De Methodol. Sociol. 2012, 114, 35-49. [CrossRef]

56. Riach, K. Exploring participant-centred reflexivity in the interview situation. Sociology 2009, 43, 356-370. [CrossRef]

57. Bamu, B.; De Schauwer, E.; Van Hove, G. I can't say I wasn't anticipating it, but I didn't see it coming in this magnitude: A Qualitative Fieldwork Experience in the North West Region of Cameroon. Qual. Rep. 2016, 21, 571-583. 
58. Lehna, C.; Sheaffer, J.; Andrade-Pulido, M.; Martinez, A.; Bishop, B. Using Nurse Shadowing as the Focus for a Recruitment Program. J. Pediatric Nurs. 2006, 21, 73-79. [CrossRef]

59. Beale, B.; Cole, R.; Hilledge, S.; McMaster, R.; Nagy, S. Impact of in-depth interviews on the interviewer: Rollercoaster ride. Nurs. Health Sci. 2004, 6, 141-147. [CrossRef]

(C) 2020 by the authors. Licensee MDPI, Basel, Switzerland. This article is an open access article distributed under the terms and conditions of the Creative Commons Attribution (CC BY) license (http://creativecommons.org/licenses/by/4.0/). 